BIODIK: Jurnal IImiah Pendidikan Biologi
ISSN 2580-0922 (online), ISSN 2460-2612 (print)
Volume 6, Nomor 02, Tahun 2020, Hal. 176-186
Available online at:
https://online-journal.unja.ac.id/biodik

Research Article OPEN ACCESS

\title{
Profil Tingkat Penalaran Ilmiah Siswa Sekolah Menengah Atas Pada Materi Ekosistem
}

\author{
(Scientific Reasoning Profile of Senior High School Students on Ecosystem Subject)
}

\begin{tabular}{|c|c|}
\hline \multicolumn{2}{|c|}{$\begin{array}{l}\text { Gina Aulia Handayani*, Sistiana Windyariani, Rizqi Yanuar Pauzi } \\
\text { Pendidikan Biologi, Fakultas Keguruan dan Ilmu Pendidikan, Universitas Muhammadiyah Sukabumi } \\
\text { Jalan R. Syamsudin SH No. } 50 \text { Kec. Cikole Kota Sukabumi-Indonesia } \\
{ }^{*} \text { Coressponding Author: ginaaulia99911@gmail.com }\end{array}$} \\
\hline Informasi Artikel & ABSTRACT \\
\hline $\begin{array}{l}\text { Submit: } 25-05-2020 \\
\text { Diterima: } 20-06-2020 \\
\text { Dipublikasikan: } 24-06-2020\end{array}$ & $\begin{array}{l}\text { Scientific Reasoning is systematic and logical thinking skills for } \\
\text { problem solving. The purpose of this preliminary study is to find out } \\
\text { the scientific reasoning profile of students in grade XI of Sukabumi } \\
\text { City Public High School on Ecosystem subject. The study was } \\
\text { conducted at the } 3^{\text {rd }} \text { week of February in one of the Sukabumi City } \\
\text { State High Schools. The research uses descriptive method with } \\
\text { quantitative approach. } 30 \text { students as the samples were taken using a } \\
\text { purposive sampling technique. The research instrument was in the } \\
\text { form of scientific reasoning test developed by Lawson, namely the } \\
\text { LCTSR (Lawson Classroom Test of Scientific Reasoning). The } \\
\text { questions used consist of } 35 \text { multiple choice questions with } 6 \\
\text { indicators of scientific reasoning: proportional, probabilistic, } \\
\text { correlational, identification and control of variables, volume } \\
\text { conservation and hypothetic-deductive. Data analysis with scoring } \\
\text { technique was applied in pairs which gave a description of the pattern } \\
\text { and level of students'scientific reasoning skills. The results showed } \\
\text { that the scientific reasoning profile of class XI State Senior High } \\
\text { School students in Sukabumi City in the year of } 2019 / 2020 \text { obtained } \\
\text { the highest reasoning pattern in the transitional operational category, } \\
\text { with a percentage of of } 76.7 \% \text {. However, the students' scientific } \\
\text { reasoning skills were categorized as less than average, with a } \\
\text { percentage of } 30.05 \% \text {. Recommendations are made to implement } \\
\text { methods, models, and learning approaches that could improve the } \\
\text { students'scientific reasoning skills. } \\
\text { Keywords: Ecosystems, Scientific Reasoning, Senior High School } \\
\text { Students }\end{array}$ \\
\hline Penerbit & ABSTRAK \\
\hline $\begin{array}{l}\text { Program Studi Pendidikan } \\
\text { Biologi, Fakultas Keguruan dan } \\
\text { Ilmu Pendidikan, Universitas } \\
\text { Jambi }\end{array}$ & $\begin{array}{l}\text { Penalaran IImiah (Scientific Reasoning) yaitu kemampuan berpikir } \\
\text { sistematis dan logis untuk menyelesaikan masalah. Tujuan dari } \\
\text { penelitian ini yaitu untuk mengetahui profil penalaran ilmiah siswa } \\
\text { kelas XI Sekolah Menengah Atas Negeri Kota Sukabumi pada materi } \\
\text { Ekosistem yang dilaksanakan pada bulan Februari di minggu ke-3 di } \\
\text { salah satu Sekolah Menengah Atas Negeri Kota Sukabumi. } \\
\text { Penelitian ini menggunakan metode deskriptif, pendekatan yang } \\
\text { digunakan yaitu pendekatan kuantitatif. Sampel diambil } \\
\text { menggunakan teknik purposive sampling berjumlah } 30 \text { siswa. } \\
\text { Instrumen penelitian ini berupa soal tes penalaran ilmiahyang } \\
\text { dikembangkan oleh Lawson yaitu tipe LCTSR (Lawson Classroom } \\
\text { Test of Scientific Reasoning). Soal yang digunakan terdiri dari } 35 \text { soal } \\
\text { pilihan ganda beralasan tipe LCTSR dengan } 6 \text { indikator penalaran }\end{array}$ \\
\hline
\end{tabular}



kontrol variabel, konservasi volume dan hipotetic-deduktif. Analisis data dengan teknik skoring dilakukan secara berpasangan yang memberikan gambaran pola dan tingkat kemampuan penalaran ilmiah siswa. Dari hasil penelitian menunjukkan bahwa profil penalaran ilmiah siswa kelas XI Sekolah Menengah Atas Negeri Kota Sukabumi tahun ajaran 2019/2020 memiliki pola penalaran yang paling tinggi berada pada kategori operasional transisional yakni sebanyak 76,7\% dan memiliki tingkat penalaran ilmiah pada kategori kurang dengan rata-rata presentase $30,05 \%$. Namun hasil ini masih harus ditingkatkan kembali dengan menggunakan metode, model dan pendekatan pembelajaran yang mampu melatihkan penalaran ilmiah siswa.

Katakunci: Ekosistem, Penalaran ilmiah, Siswa Sekolah Menengah Atas.

This BIODIK : Jurnal IImiah Pendidikan Biologi is licensed under a CC BY-NC-SA (Creative Commons Attribution-ShareAlike 4.0 International License)

\section{PENDAHULUAN}

Di Era globalisasi saat ini khususnya di Indonesia, upaya untuk meningkatkan kualitas sumber daya manusia terus dikembangkan salah satunya melalui bidang pendidikan. Karena pendidikan memiliki peran penting sehingga perlu ikut berperan aktif dalam meningkatkan kualitas juga kuantitas pola berpikir siswa. Dalam meningkatkan pola berpikir siswa, perlu didukung melalui proses pembelajaran yang tepat, agar kemampuan atau keterampilan siswa dapat berkembang dengan baik (Rahmawati, 2018). Peran guru dituntut untuk memiliki pemahaman tentang paradigma pembelajaran abad-21 yang diterapkan sebagai kerangka pengetahuan dalam proses pembelajaran. Salah satu kemampuan berpikir yang penting dikuasai oleh peserta didik adalah kemampuan berpikir tingkaat tinggi (High Order Thinking). Berpikir tingkat tinggi (HOTS) dalam pembelajaran penting dikuasai oleh peserta didik karena HOTS merupakan salah satu tuntutan pendidikan abad-21 (Madang et al., 2019).

Salah satu karakteristik pada keterampilan abad 21 yaitu menuntut sumber daya manusia yang mampu berpikir dan bernalar secara ilmiah untuk menyelesaikan berbagai macam permasalahan (Zulfaidhah, Z., Palenewen, E., \& Hardoko, A, 2018). Karakteristik keterampilan abad 21 yang harus dimiliki oleh siswa antara lain yaitu: penalaran (reasoning), pemecahan masalah (problem solving), komunikatif dan kolaboratif (Hakim, N. (2015). Salah satu keterampilan abad 21 yang perlu di latihkan yaitu keterampilan penalaran ilmiah (Scientific reasoning). ( Saad et al., 2017). Penalaran ilmiah dimaksudkan sebagai kemampuan berpikir sistematis dan logis untuk menyelesaikan masalah dengan menggunakan metode ilmiah, meliputi proses mengevaluasi fakta, membuat prediksi dan hipotesis, menentukan dan mengontrol variabel, merancang dan melakukan eksperimen, mengumpulkan data, menganalisis data dan mengambil kesimpulan. Penalaran ilmiah sangat penting untuk dilatihkan karena merupakan landasan dari proses penemuan dan juga menjadi dasar bagi perkembangan keterampilan lain seperti keterampilan berpikir kritis (berpikir tingkat 
tinggi) dan pemecahan masalah (Nugraha, M. G., Kirana, K. H., Utari, S., Kurniasih, N., Nurdini, N., \& Sholihat, F. N, 2017).

Berdasarkan data dari Organization for Econimic Co-Operation and Development (OECD) hasil tes berdasarkan Program for International Student Assessment (PISA) pada tahun 2009 menunjukan bahwa rendahnya kemampuan penalaran ilmiah peserta didik di negara Indonesia menduduki peringkat ke 60 dari 65 negara serta memiliki skor 385, angka ini terbilang rendah dibandingkan dengan skor rata-rata yang diterapkan oleh OECD yakni skor sebesar 501 terutama pada skala sains. Penalaran ilmiah (Scientific reasoning) merupakan kemampuan berpikir sistematis dan logis untuk menyelesaikan masalah dengan menggunakan metode ilmiah meliputi tahap mengevaluasi fakta, membuat prediksi dan hipotesis, menentukan dan mengontrol variabel, merancang dan melakukan eksperimen, mengumpulkan data, menganalisis data dan mengambil kesimpulan (Purwana, 2016; Koenig, 2012; Zimmerman, 2007; Ammer, 2005).

Saptono $S$ et al. (2013) menyebut bahwa penalaran ilmiah merupakan salah satu keterampilan yang diharapkan dapat diajarkan di kelas sains sebagai upaya untuk mempersiapkan peserta didik agar mereka berhasil dalam menghadapi tantangan globalisasi. Untuk mengakomodasi hal ini pengembangan kurikulum hendaknya memperhatikan aspek pengembangan kemampuan problem solving, reasoning, konseptualisasi dan analisis.

Penalaran ilmiah yang dimaksdu keterampilan kognitif dalam memahami dan mengevaluasi informasi-informasi ilmiah. Sub-keterampilan untuk penilaian penalaran ilmiah, yaitu konservasi berat dan volume, penalaran proporsional, pengendalian variabel, penalaran probabilitas, penalaran korelasi, dan penalaran hipotetis-deduktif (Sigiro, O. N., Sigit, D. V., \& Komala, R, 2017). Koenigh et al. (2012) menyatakan bahwa penalaran ilmiah berhubungan dengan kemampuan yang digunakan saat praktik ilmiah dan berhubungan dengan pengumpulan serta analisis bukti. Untuk meningkatkan keterampilan penalaran ilmiah, dibutuhkan strategi pembelajaran dan perangkat pembelajaran yang memadai dan pendidik benar-benar menciptakan situasi belajar agar siswa dapat berperan aktif selama proses pembelajaran. Salah satu strategi pembelajaran melalui eksperimen dan perangkat pembelajaran yang dapat digunakan adalah lembar kerja. Oleh karena itu, model pembelajaran berbasis proyek yang dibantu dengan Scientific Creative and Critical Worksheet (SCCW) dapat melatihkan dan meningkatkan keterampilan penalaran ilmiah siswa. (Utami, N., Karim, S., Saepuzaman, D., \& Feranie, S, 2019).

Dalam pembelajaran Biologi sangat erat hubungannya terhadap berbagai gejala alam dalam kehidupan sehari-hari, hal ini ditunjukan yaitu untuk mengembangkan keterampilan berpikir analitik, bernalar, berpikir deduktif dan induktif melalui konsep dan prinsip Biologi. Dalam proses pembelajaran Biologi hendaknya menekankan siswa untuk berpikir secara logis, rasional dan lebih luas yang berdasarkan pengalaman sehingga berdampak penting bagi penalaran ilmiah peserta didik. Desain pembelajaran dapat meningkatkan keterampilan penalaran ilmiah Nehru, N., \& Syarkowi, A. (2017). 


\section{METODE PENELITIAN}

Penelitian ini menggunakan metode deskriptif dan pendekatan kuantitatif yaitu pendekatan yang cenderung fokus terhadap suatu permasalahan (Sugiyono, 2013). Prosedur penelitian meliputi 3 tahap yaitu tahap persiapan, tahap pelaksanaan, dan dan tahap menarik kesimpulan.

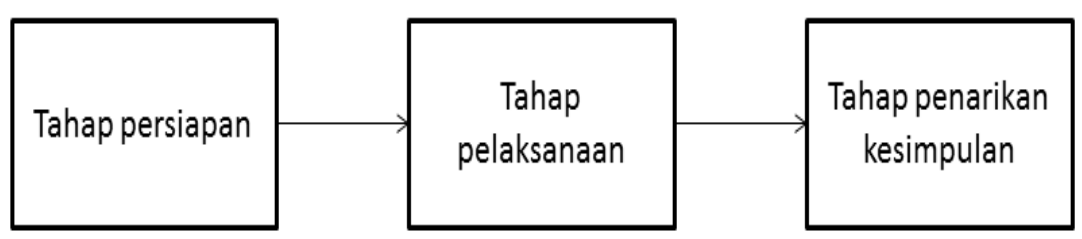

\section{Gambar 1 : Prosedur Penelitian}

Pada tahap persiapan dengan melakukan study literature, memilih subjek penelitian,menyiapkan surat izin penelitian, merancang instrumen, judgment intrument, menyiapkan intrumen berupa soal.

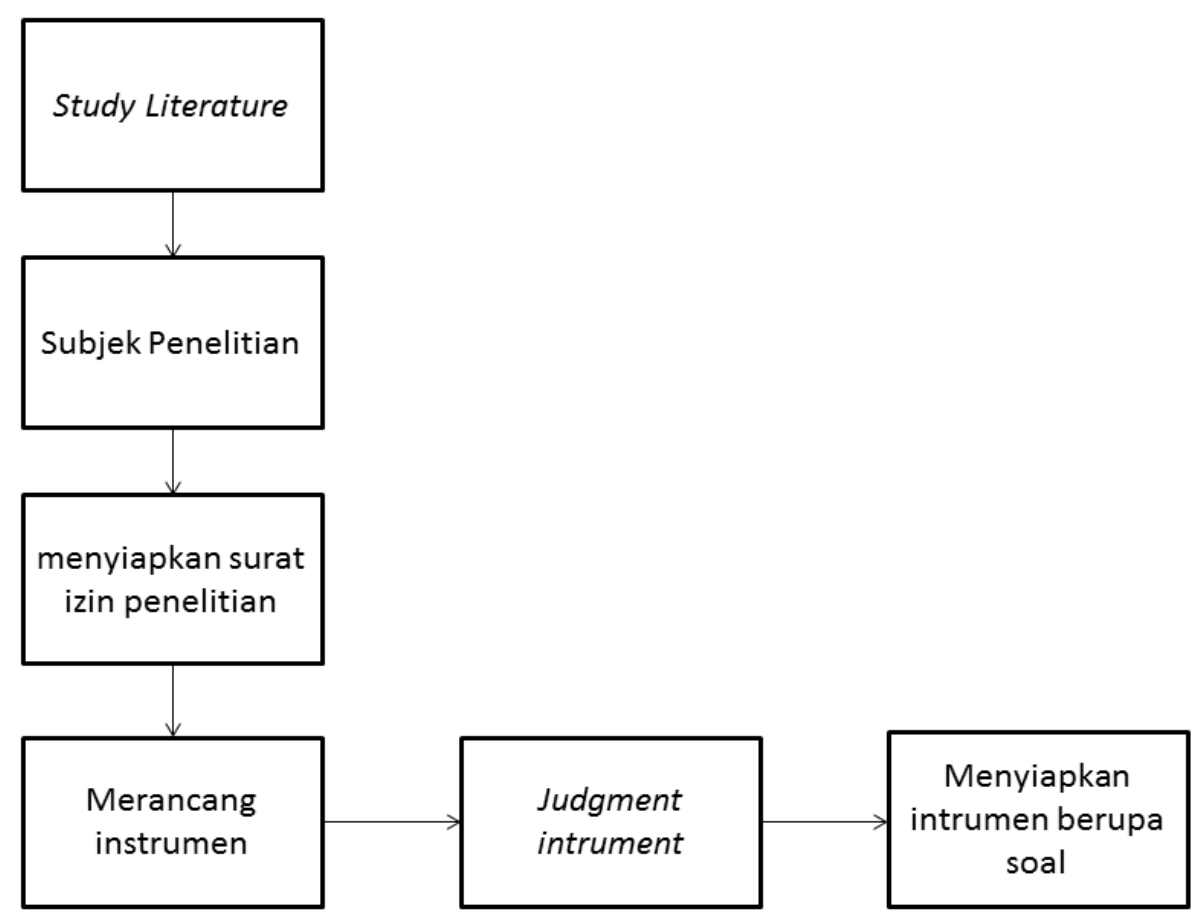

Gambar 2. Tahap Persiapan

Kemudian tahap pelaksanaan dengan menyebarkan intrumen soal kepada siswa lalu tahap akhir mengolah data hasil penelitian, membuat pembahasan dan menarik kesimpulan hasil penelitian. Sampel yang digunakan sebanyak 30 siswa, sampel ini diambil menggunakan teknik purposive sampling yakni dilakukan dengan cara mengambil subjek bukan didasarkan atas strata, random atau daerah tetapi 
didasarkan atas adanya tujuan tertentu, melihat dari kemampuan berpikir tingkat tinggi siswa dan penelitian ini dilaksanakan pada bulan Februari 2020 diminggu ke3.

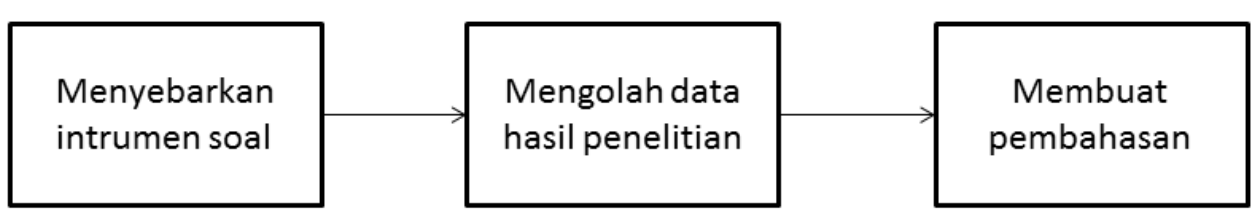

Gambar 3. Tahapan Pelaksanaan

Instrumen penelitian berupa tes penalaran ilmiah berdasarkan tipe LCTSR yang terdiri atas 35 butir soal pilihan ganda beralasan yaitu 19 pertanyaan konten dan 16 pilihan alasan. Indikator yang digunakan ada 6 antara lain proporsional, probabilistik, korelasional, konservasi volume, identifikasi dan kontrol variabel, hipotetic-deduktif dan instrumen yang digunakan sudah terstandar menyesuaikan dengan indikator penalaran ilmiah yang dikembangkan oleh Lawson yaitu Lawson Classroom Test Scientific Reasoning (LCTSR). Teknik analisis data yang digunakan yaitu deskriptif untuk memberikan gambaran pola dan tingkat kemampuan penalaran ilmiah siswa. Pada tahap skoring setiap butir soal diberi skor 1 apabila soal konten dan soal alasan benar, apabila salah satu dari soal konten dan soal alasan salah maka diberi skor 0 begitupun apabila kedua jawabannya salah diber skor 0 . Adapun kategori pola penalaran ilmiah.

Tabel 1. Kategori Kelompok Pola Penalaran

\begin{tabular}{ccc} 
No & Total skor $(\%)$ & Kategori \\
\hline 1 & $0-4$ & Operasional konkret \\
2 & $5-8$ & Operasional Transisional \\
3 & $9-12$ & Operasional Formal
\end{tabular}

Pada tahap skoring setiap butir soal diberi skor 1 apabila soal konten dan soal alasan benar, apabila salah satu dari soal konten dan soal alasan salah maka diberi skor 0 begitupun apabila kedua jawabannya salah diber skor 0 . Adapun kategori tingkat penalaran ilmiah dapat dilihat pada tabel 2.

Tabel 2. Kategori Tingkat Penalaran IImiah

\begin{tabular}{cc} 
Skor (\%) & Kategori \\
\hline $81-100$ & Sangat baik \\
$61-80$ & Baik \\
$41-60$ & Cukup \\
$21-40$ & Kurang \\
$0-20$ & Sangat Kurang \\
\hline
\end{tabular}


Selanjutnya untuk menentukan tingkat penalaran ilmiah siswa dilakukan analisis ketercapaian setiap indikator penalaran ilmiah dengan menghitung presentase total kemampuan penalaran ilmiah menggunakan rumus yang dikemukakan oleh Arikunto (2010) sebagai berikut :

$$
P=\frac{f}{n} x 100 \%
$$

$\begin{array}{ll}\mathrm{P} & \text { : Presentase jawaban } \\ F & \text { : Frekuensi jawaban siswa } \\ n & \text { : Jumlah siswa }\end{array}$

\section{HASIL DAN PEMBAHASAN}

Penalaran ilmiah (Scientific reasoning) dapat diartikan sebagai kemampuan berpikir sistematis dan logis untuk menyelesaikan masalah dengan menggunakan metode ilmiah meliputi tahap mengevaluasi fakta, membuat prediksi dan hipotesis, menentukan dan mengontrol variabel,merancang dan melakukan eksperimen, mengumpulkan data,menganalisis data dan mengambil kesimpulan (Purwana, 2016; Koenig, 2012; Zimmerman, 2007; Ammer, 2005). Pengembangan pembelajaran meningkatkan penalaran ilmiah (Fitriyati, I., Hidayat, A., \& Munzil, M, 2017).

Indikator yang diamati dari kemampuan penalaran ilmiah ini antara lain yaitu proporsional, probabilistik, korelasional, konservasi volume, identifikasi dan kontrol variabel, hipotetic-deduktif. Penelitian ini dilakukan dengan menggunakan lembar soal keterampilan penalaran ilmiah pada materi ekosistem. Adapun penelitian ini dilakukan di kelas XI SMA Negeri Kota Sukabumi berjumlah 30 siswa.

\section{Data hasil observasi kemampuan penalaran ilmiah siswa}

Pada penelitian ini jawaban siswa pada soal ini dikelompokan menjadi tiga kategori pola penalaran ilmiah antara lain yaitu operasional konkret, operasional transisional dan operasional formal. Adapun hasil observasi dari siswa kelas XI SMA Negeri Kota Sukabumi yaitu sebagai berikut:

Tabel 3. Data Hasil LCTSR untuk Pola Penalaran IImiah

\begin{tabular}{llcc}
\hline No & Pola Penalaran & Jumlah siswa & Presentase (\%) \\
\hline 1 & Operasional konkret & 6 orang & $20 \%$ \\
2 & Operasional Transisional & 23 orang & $76,7 \%$ \\
3 & Operasional Formal & 1 orang & $3,3 \%$ \\
\hline
\end{tabular}

Berdasarkan hasil penelitian pada Tabel 3 menunjukan bahwa siswa SMA kelas XI tersebut memiliki persentase paling tinggi terdapat pada kategori pola penalaran ilmiah tahap Operasional Transisional yaitu sebanyak 23 orang $(76,7 \%)$, menurut Piaget (dikutip dalam Pasaribu, 2013) pada tahap ini individu telah mampu menyelesaikan permasalahan yang berkaitan dengan penalaran proporsional dan 
pengontrolan variabel. Pola pemikiran siswa masih terbatas pada dua pola penalaran tersebut walaupun sudah mulai kearah penyelidikan serta hubungan sebab akibat dalam menilai sesuatu siswa telah menggunakan logika yang sederhana sehingga penilaian memberika pernyataan yang obyektif. Dan sebanyak 6 orang (20\%) berada pada tahap operasional konkret yaitu siswa hanya mampu menerapkan logika berpikir pada hal-hal yang konkret, menurut Eggen (dikutip dalam Pasaribu, 2013) pada tahap ini siswa hanya mampu membentuk konsep, memecahkan masalah dan melihat hubungan. Sedangkan hanya 1 orang $(3,3 \%)$ saja yang berada pada tahap operasional formal. Hasil ini tidak sesuai dengan teori perkembangan kognisi anak menurut Piaget (dikutip dalam Sutarno, 2014) yakni bahwa anak yang berusia 11 tahun ke atas seharusnya telah memiliki kemampuan penalaran pada level operasional formal.

Menurut Pasaribu (2013) pada tahap ini penalaran dan logika dalam memecahkan persoalan yang dihadapi telah berkembang, individu seharusnya telah mampu menyelesaikan permasalahan yang berhubungan dengan penalaran proporsional, penalaran korelasional kontrol variabel, penalaran konservasi volume, penalaran probabilistik dan hipotetic-deduktif.

Tabel 4. Hasil Tingkat Penalaran IImiah SiswaSMA Kelas XI

\begin{tabular}{clcc} 
No & Indikator Penalaran IImiah & $(\%)$ & Kategori \\
\hline 1 & Proporsional & $42,5 \%$ & Cukup \\
2 & Probabilistik & $8,9 \%$ & Sangat Kurang \\
3 & Korelasional & $21,1 \%$ & Kurang \\
4 & Identifikasi dan Kontrol & $41,1 \%$ & Cukup \\
& variabel & & \\
5 & Konservasi Volume & $26,7 \%$ & Kurang \\
6 & Hipotetic-deduktif & $40 \%$ & Kurang \\
\hline Rata-rata & & $30,05 \%$ & Kurang
\end{tabular}

Berdasarkan data pada tabel 4 kategori tingkat penalaran ilmiah siswa SMA kelas XI memperoleh hasil rata-rata sebanyak 30,05\% termasuk dalam kategori kurang untuk seluruh indikator penalaran ilmiah. Indikator yang paling rendah persentasenya yaitu probabisistik yakni $8,9 \%$ dari seluruh siswa dan indikator penalaran ilmiah yang paling tinggi persentasenya yaitu penalaran proporsional yakni $42,5 \%$.

Berdasarkan tabel diatas, dapat dilihat persentase indikator penalaran ilmiah paling tinggi yaitu penalaran proporsional yakni sebesar $42,5 \%$ dengan kategori cukup. Penalaran proporsional merupakan kemampuan penalaran sistem dua variabel yang memiliki hubungan fungsi linear yaitu mengarah ke kesimpulan tentang fenomena yang dapat ditandai dengan rasio kontan (Shofiyah et al., 2013). Pada indikator penalaran ilmiah probabilistik memiliki persentase yakni sebesar $8.9 \%$ dengan kategori sangat kurang. Penalaran probabilistik merupakan penalaran yang menggunakan informasi untuk memutuskan apakah suatu kesimpulan berkemungkinan benar atau salah dan hal-hal yang memiliki kemungkinan terjadi dalam perhitungan peluang (Tawil, 2008). 
Pada indikator penalaran ilmiah identifikasi dan kontrol variabel memperoleh persentase yakni sebesar $41,1 \%$ dengan kategori cukup. Indikator penalaran identifikasi dan kontrol variabel yaitu kemampuan penalaran yang dimiliki siswa untuk mengontrol variabel. Kemampuan ini diperlukan dalam proses penyelidikan ilmiah, hal ini dikarenakan selama proses penyelidikan melibatkan banyak variabel dan mengontrol variabel untuk menganalisis hubungan antar variabel (Dessy, 2017). Pada Indikator penalaran ilmiah korelasional memperoleh persentase yakni sebesar $21,1 \%$ dengan kategori kurang. Penalaran korelasional merupakan penalaran yang digunakan untuk mengidentifikasi dan menentukan hubungan timbal balik antar variabel (Lawson, 2004). .

Pada indikator penalaran ilmiah konservasi volume memperoleh persentase $26,7 \%$ dengan kategori kurang. Penalaran konservasi merupakan penalaran yang digunakan untuk memahami bahwa sifat-sifat tertentu pada benda tidak berubah. Hasil penelitian menunjukan bahwa siswa masih kurang tepat dalam menjawab soal konten dan soal alasan pada penalaran konservasi volume. Gejala lemahnya kemampuan konservasi disebabkan oleh masih tertanamnya pengetahuan awal (intuisi) siswa tentang konsep-konsep yang selama ini dimiliki (Manurung, 2003). Pada indikator penalaran ilmiah hipotetic-deduktif memperoleh persentase yakni sebesar $40 \%$ dengan kategori kurang. Penalaran hipotetic-deduktif yaitu kemampuan membentuk hipotesis dari teori-teori umum yang diikuti oleh deduksi untuk mengembangkan solusi terhadap masalah yang akan terjadi dalam eksperimen (Han, 2013).

Berdasarkan hasil dari penelitian yang saya lakukan ini menunjukan bahwa tingkat penalaran ilmiah siswa SMA kelas XI masih berada dalam kategori kurang dengan persentase rata-rata $30,05 \%$. Dari enam indikator penalaran ilmiah menunjukan bahwa sebagian besar siswa kurang tepat dalam menjawab pasangan soal konten dan alasan dengan benar. Rendahnya kemampuan penalaran ilmiah siswa tersebut mengindikasikan bahwa siswa tidak mendapatkan pembelajaran yang relevan dengan faktor-faktor yang dibutuhkan untuk perkembangannya. Salah satu faktor yang mempengaruhi perkembangan penalaran ilmiah siswa tersebut yaitu dengan menggunakan pendekatan dan model pembelajaran yang saintifik. Rendahnya kemampuan penalaran ilmiah siswa kelas X SMA Negeri Kota Sukabumi dilihat dari observasi lapangan secara langsung bahwa pembelajaran dikelas belum secara maksimal melatihkan pada proses sains tetapi lebih difokuskan pada aspek pengetahuannya, hal ini dapat dilihat dari hasil beberapa penelitian lain bahwa rendahnya kemampuan penalaran ilmiah karena belum maksimalnya pembelajaran yang melatihkan kemampuan proses sains siswa. Selain itu rendahnya kemampuan ini dilihat dari capaian siswa Indonesia menurut data dari OECD hasil tes berdasarkan PISA pada tahun 2009 menunjukan bahwa rendahnya kemampuan penalaran ilmiah siswa di negara Indonesia menduduki peringkat ke 60 dari 65 negara serta memiliki skor 385, angka ini terbilang rendah dibandingkan dengan skor rata-rata yang diterapkan oleh OECD yakni skor sebesar 501 terutama pada skala sains. Agar pembelajaran Biologi dapat mendorong dan melatihkan kemampuan penalaran ilmiah maka pembelajaran di kelas harus difokuskan pada proses sains menggunakan pendekatan atau metode ilmiah. Berdasarkan beberapa penelitian 
terdapat banyak model dan metode pembelajaran yang berorientasi pada pendekatan saintifik antara lain yaitu model pembelajaran inquiry, problem solving, problem based learning, discovery learning dan masih banyak model/metode lainnya.

\section{KESIMPULAN}

Kesimpulan dari hasil penelitian pendahuluan ini menunjukan bahwa profil penalaran ilmiah siswa kelas XI SMA Negeri Kota Sukabumi tahun ajaran 2019/2020 masih dalam kategori kurang karena pembelajaran dikelas belum secara maksimal melatihkan pada proses sains tetapi lebih difokuskan pada aspek pengetahuannya, namun hasil tersebut masih harus dilatihkan dan ditingkatkan kembali dengan menggunakan metode, model dan pendekatan pembelajaran yang menekankan pada proses sains yang mampu melatihkan penalaran ilmiah siswa.

\section{UCAPAN TERIMAKASIH}

Ucapan terima kasih saya sampaikan kepada berbagai pihak yaitu dosen pembimbing, guru-guru SMA di Sukabumi, kedua orangtua dan teman-teman seperjuangan yang telah membantu dalam penelitian dan penyusunan jurnal ini

\section{DAFTAR PUSTAKA}

Agustina. D, Ida K dan Irma R.M. (2017). Penerapan Pembelajaran Berbasis Stem (Science, Technology, Engineering And Mathematics) Untuk Meningkatkan Kemampuan Control Of Variable Siswa SMP Pada Hukum Pascal. Prosiding Seminar Nasional Fisika (E-Journal) SNF201. Vol VI. p-ISSN: 2339-0654 eISSN: 2476-9398.

Arikunto, S. (2010). Prosedur Penelitian Suatu Pendekatan Praktik. Jakarta: Rineka Cipta.

Eggen, P.D dan Kauchak, D.P. (1997). Strategies For Teacher Teaching Content And Thingking Skills. Boston : Allyn\& Bacon.

Fitriyati, I., Hidayat, A., \& Munzil, M. (2017). PENGEMBANGAN PERANGKAT PEMBELAJARAN IPA UNTUK MENINGKATKAN KEMAMPUAN BERPIKIR ILMIAH DAN BERPIKIR TINGKAT TINGGI SISWA SEKOLAH MENENGAH PERTAMA. Jurnal Pembelajaran Sains, 1(1), 27-34.

Hakim, N. (2015). Penerapan Project-Based Learning Dipadu Group Investigetion Untuk Meningkatkan Motivasi, dan Hasil Belajar Mahasiswa Pendidikan Biologi Universitas Muhammadiyah Malang. Jurnal BIODIK, 1(1).

Han, J. (2013). Scientific reasoning: Research, development, and assessment. The Ohio State University.

Koenig, K, Schen, M, and Bao, L. (2012). Explicitly targeting pre-service teacher scientific reasoning abilities and understanding of nature of science through an introductory science course. Science Educator. Vol 21(2).

Lawson, A. E. (2004). The nature and development of scientific reasoning: A synthetic view. International Journal of Science and Mathematics Education, 2(3), 307-338. https://doi.org/10.1007/s10763-004-3224-2. 
Madang, K., Tibrani, M., \& Santoso, L. M. (2019). Implementation of Problem Based Learning ( PBL ) Models Supported by Pedagogical Agents for Higher Order Thinking Skills ( HOTS ) in Learning Invertebrate Zoology Implementasi Model Problem Based Learning ( PBL ). BIODIK: Jurnal IImiah Pendidikan Biologi, 5(3), 262-272.

Manurung, D. S. R. (2003). Identifikasi Kemampuan Berpikir Logik Tentang Konservasi Besaran Bagi Siswa SD. Mimbar Pendidikan, 22(2), 19-25.

Nehru, N., \& Syarkowi, A. (2017). Analisis Desain Pembelajaran Untuk Meningkatkan Literasi Sains Berdasarkan Profil Penalaran IImiah. WAPFI (Wahana Pendidikan Fisika), 2(1). https://doi.org/10.17509/wapfi.v2i1.4867.

Nugraha, M. G., Kirana, K. H., Utari, S., Kurniasih, N., Nurdini, N., \& Sholihat, F. N. (2017). Problem Solving-Based Experiment untuk Meningkatkan Keterampilan Penalaran Ilmiah Mahasiswa Fisika. Jurnal Penelitian \& Pengembangan Pendidikan Fisika, 3(2), 137-144. https://doi.org/10.21009/1.03203.

OECD (2009). Take the Test: Sample Questions from Oecd's PISA Assessments. ISBN 978-92-64-05080-8.

Pasaribu, dkk. (2013). Pemetaan Tingkat Perkembangan Kognitif Siswa Kelas XI SMA LAB School Palu. Prosiding Seminar Nasional Sains dan Matematika II Jurusan Pendidikan MIPA FKIP UNTAD 2013. ISBN 978-602-8824-49-1.

Piaget, J. (1964). Cognitive development in children : development and learning. Journal of Research in Sciences Teaching, 2,176-186.

Purwana, U, Liliasari, dan Rusdiana, D. (2016). Profil Kompetensi Awal Penalaran Ilmiah (Scientific Reasoning) Mahasiswa pada Perkuliahan Fisika Sekolah. Prosiding Simposium Nasional Inovasi dan Pembelajaran Sains. p. 753-756.

Puspita, D.I (2016). Analisis Tingkat Kemampuan Scientific Reasoning Siswa SMA Kelas X IPA se Kota Tegal. Prosiding Seminar Nasional Sains dan Entrepreneurship III tahun 2016. Pendidikan sains [198-205].

Rahmawati, W. (2018). Pengaruh Pendekatan Pembelajaran Socioscientific Issues (SSI) Pada Model Problem Solving Learning Terhadap Kemampuan Berpikir Kreatif Peserta Didik Pada Materi Pencemaran Air. Skripsi FKIP, Pendidikan Biologi, Universitas Muhammadiyah Sukabumi: Sukabumi.

Saad, M. I. M., Baharom, S., \& Mokhsein, S. E. (2017). Scientific reasoning skills based on socio-scientific issues in the biology subject. International Journal of ADVANCED AND APPLIED SCIENCES, 4(3), 13-18.

https://doi.org/10.21833/ijaas.2017.03.003

Saptono S., Rustaman N Y, Saefudin, Widodo A. (2013). Model Integrasi Atribut Assessment Formatif (IAAF) Dalam Pembelajaran Biologi Sel Untuk Mengembangkan Kemampuan Penalaran dan Berpikir Analitik Mahasiswa Calon Guru. Jurnal Pendidikan IPA Indonesia. JPII 2 (1) (2013) 31-40.

Sari L.S, Zulhelmi \& Azizahwati, (2019). Analisis Kemampuan Scientific Reasoning Siswa Kelas X Sma Negeri Se-Kecamatan Tampan Pekanbaru Pada Materi Usaha Dan Energi. JOM FKIP Vol.6 (2).

Shofiyah, N., Supardi, Z. A. I., \& Jatmiko, B. (2013). Mengembangkan penalaran ilmiah (Scientific reasoning) siswa melalui model pembelajran 5E pada siswa kelas X sman 15 surabaya. Jurnal Pendidikan IPA Indonesia, 2(1), 83-87. 
https://doi.org/10.15294/jpii.v2i1.2514.

Sigiro, O. N., Sigit, D. V., \& Komala, R. (2017). Hubungan Efikasi Diri Dan Penalaran IImiah Dengan Hasil Belajar Biologi Siswa SMA. Biosfer: Jurnal Pendidikan Biologi, 10(2), 30-34.

Sutarno (2014). Profil Penalaran IImiah (Scientific Reasoning) Mahasiswa Program Studi Pendidikan Fisika Universitas Bengkulu Tahun Akademik 2013/2014. Seminar Nasional dan Rapat Tahunan Bidang MIPA 2014. ISBN 978-60270491-0-9.

Tawil, M. (2008). Kemampuan Penalaran Formal dan Lingkungan Pendidikan Keluarga Dikaitkan dengan Hasil Belajar Fisika Siswa Kelas X SMA Negeri 1 Sungguminasa Kabupaten Gowa. In Jurnal Pendidikan dan Kebudayaan (Vol. 14, Issue 75, p. 1047). https://doi.org/10.24832/jpnk.v14i75.371.

Utami, N., Karim, S., Saepuzaman, D., \& Feranie, S. (2019). PENGARUH SCIENTIFIC CREATIVE AND CRITICAL WORKSHEET (SCCW) DALAM MENINGKATKAN KETERAMPILAN PENALARAN ILMIAH SISWA SMA PADA TOPIK MOMENTUM IMPULS. In PROSIDING SEMINAR NASIONAL FISIKA (EJOURNAL) (Vol. 8, pp. SNF2019-PE).

Zulfaidhah, Z., Palenewen, E., \& Hardoko, A. (2018). Needs Analysis in the Problem Based Learning (PBL) Model Tools and Problems Regarding 7th Grade Students' Science Learning Outcome at SMPN 2 Bongan. BIODIK, 4(1), 48-59. https://doi.org/10.22437/bio.v4i1.5508. 